\title{
A COMUNIDADE DAS SINGULARIDADES QUAISQUER: A COMUNIDADE QUE VEM DE GIORGIO AGAMBEN
}

\author{
Alessandra Soares Brandão ${ }^{1}$ \\ Júlio César Alves da Luz ${ }^{2}$
}

Resenha de: AGAMBEN, Giorgio. A Comunidade que vem. Trad. de Cláudio Oliveira. Belo Horizonte: Autêntica Editora, 2013.

Num contexto em que ruíam, no leste europeu, as experiências socialistas frustradas das repúblicas da extinta União Soviética, quando o espectro da "ameaça comunista" parecia deixar de assombrar as potências capitalistas do Ocidente, as desilusões marcadas pelo colapso dos projetos utópicos de comunidade alentados pela esquerda socialista aprofundavam-se face à realidade inexorável do suposto triunfo e perpetuidade da sociedade capitalista. Nesse contexto, assim assinalado pelas malogradas propostas de transformação social, Giorgio Agamben as coloca em questão e procura, em A Comunidade que vem, repensar o ideal político de comunidade sob um viés diferente das perspectivas comunitárias que então esboroavam.

Contudo, como observa Raul Antelo, essa comunidade não tem nada a ver com o comunismo ou o comunitarismo, e, por outro lado, que vem não remete à ideia de futuro. "Quer dizer inoperante e decreativa. Impolítica. Que está sempre chegando no meio de uma coletividade e é, justamente, porque nunca acaba de chegar, que ela resiste ao coletivo e até mesmo ao indivíduo (2007, p. 29). Uma comunidade não pressuposta, que não se funda em nenhuma reivindicação identitária, em nenhum conceito ou propriedade - uma comunidade de singularidades quaisquer.

"O ser que vem", Agamben escreve na primeira linha de seu texto, "é o ser qualquer" (2013, p. 09). Não o qualquer ser, ser genérico, tomado na sua indiferenciação quanto a uma propriedade compartilhada com outros seres, mas o ser qualquer, que não é nem universal, nem individual, o qual forma comunidade, mas é considerado precisamente em sua singularidade, em seu ser tal qual é. Para o autor, o ser qualquer, a singularidade, não apresenta nenhuma condição de pertença, nada que a encerre sob uma identidade num conjunto.

\footnotetext{
Nesta, o ser-qual é recuperado do seu ter esta ou aquela propriedade, que identifica o seu pertencimento a este ou aquele conjunto, a esta ou aquela classe (os vermelhos, os franceses, os muçulmanos) - e recuperado não para uma outra classe ou para a simples ausência genérica de todo pertencimento, mas para o seu ser-tal, para o próprio pertencimento (idem, p. 10).
}

\footnotetext{
${ }^{1}$ Professora do Programa de Pós-Graduação em Ciências da Linguagem da Universidade do Sul de Santa Catarina. E-mail: alessandra.b73@gmail.com

${ }^{2}$ Doutorando do Programa de Pós-Graduação em Ciências da Linguagem da Universidade do Sul de Santa Catarina. E-mail: juliodaluz82@gmail.com
}

BRANDÃO, Alessandra Soares; LUZ, Júlio César Alves da. A comunidade das singularidades quaisquer: a comunidade que vem de Giorgio Agamben. Crítica Cultural - Critic, Palhoça, SC, v. 9, n. 2, p. 339-343, jul./dez. 2014. 
Porque não há em sua comunidade uma propriedade que lhes esteja acima e que lhes imponha, desse modo, um destino histórico a cumprir, às singularidades quaisquer não cabe nenhuma tarefa a realizar. Nesse sentido, segundo o autor, o ser qualquer vive numa condição límbica, isto é, na tradição cristã, a condição da pena reservada às crianças não batizadas. Diferentemente da pena aflitiva dos condenados ao inferno, sua pena é tão-somente privativa: a ausência eterna da visão de Deus; uma experiência, no entanto, sem dor, já que ignoram estar privados do bem supremo, porquanto tenham apenas "o conhecimento natural e não o sobrenatural, que foi implantado em nós pelo batismo" (idem, p. 13). Esquecidos, pois, por Deus, os habitantes do Limbo encontramse, por outro lado, desde sempre esquecidos de Deus, por cuja ausência - que desconhecem - não podem sofrer. Vivendo, assim, no abandono divino, esses ressuscitados sem destino vivem alegremente sem um destino a cumprir.

A comunidade que vem não tem essência; ela se constitui na sua impropriedade. Nela, as singularidades quaisquer, de acordo com o autor, encontram-se eximidas de qualquer papel numa suposta obra comum pela qual devam lutar. Não há compromisso algum com qualquer destino a perseguir, como tampouco haveria uma origem que se lhe atribuísse o dever de preservar ou, se perdida, resgatá-la. Razão pela qual somente assim, consoante Agamben, é que se poderia admitir, aliás, uma ética possível:

O fato do qual deve partir todo discurso sobre a ética é que o homem não é nem há de ser ou realizar nenhuma essência, nenhuma vocação histórica ou espiritual, nenhum destino biológico. Somente por isso algo como uma ética pode existir: pois é claro que se o homem fosse ou tivesse que ser esta ou aquela substância, este ou aquele destino, não haveria nenhuma experiência ética possível - haveria apenas tarefas a realizar (idem, p. 45).

Contudo, não obstante isentas de quaisquer deveres a realizar, as singularidades não permanecem paralisadas, condenadas a circunstâncias em que se imobilizam desengajadas. Pelo contrário, Agamben assume, nesse texto, uma perspectiva política que contradiz os diagnósticos pessimistas tão frequentemente criticados em outras obras suas. Com efeito, como observa Georges Didi-Huberman (2011), não é outro senão um olhar apocalíptico, por exemplo, que o filósofo italiano expressa ao falar - na sua leitura de $O$ narrador, de Walter Benjamin, - da destruição da experiência histórica na modernidade. Aquele processo que Benjamin, sob o contexto da Segunda Guerra Mundial, havia percebido e designado como o do declínio da experiência, Agamben o reduz, numa visão catastrofista que contraria a compreensão dialética benjaminiana do processo histórico, à concepção radical da total destruição da experiência.

É também um diagnóstico pessimista, aliás, - cuja persistência no pensamento contemporâneo Didi-Huberman critica - que atravessa o trabalho com o qual Giorgio Agamben, poucos anos após a publicação de $A$ comunidade que vem, aufere maior notoriedade sobretudo no meio acadêmico: Homo sacer: o poder soberano e a vida nua. O homo sacer é uma figura do direito romano arcaico, cuja condenação por delito cometido o tornava matável e, no entanto, ao mesmo tempo insacrificável, - figura que, para o autor, exprime a condição do que ele denomina vida nua - aquela vida da "classe que, de fato, se não de direito, é excluída da política" (2010, p. 172) - exposta à violência do poder soberano. Ora, no contexto biopolítico contemporâneo, assinalado 
pela crescente politização do corpo biológico, assevera Agamben, somos todos, ainda que potencialmente, homines sacri. Afinal, não é senão a vida nua com a qual nos deparamos sujeita a uma violência sem precedentes, seja nos campos de refugiados na Europa, ou nas prisões onde se isolam perseguidos políticos sob governos ditatoriais, ou, então, nas periferias das cidades, principalmente nos países mais pobres.

Porém, não obstante diagnósticos assim um tanto apocalípticos, que parecem não vislumbrar saídas, é outro o sentido expresso pela perspectiva assumida por Agamben em A comunidade que vem. Isso porque, como adverte o autor, se a singularidade qualquer não é nem deve realizar nenhuma essência, nenhuma obra, nenhum destino, isso não significa que não seja, ou que não deva ser alguma coisa. Há, pelo contrário, algo que ela é e tem de ser, "mas este algo não é uma essência, não é, aliás, propriamente uma coisa: é o simples fato da própria existência como possibilidade ou potência" (2013, p. 45). O ser qualquer, segundo o filósofo, "tem sempre um caráter potencial", mas que "não é potente apenas deste ou daquele ato específico": "propriamente, qualquer é o ser que pode não ser, pode a própria impotência" (idem, p. 39).

Remetendo-se à distinção aristotélica entre potência e ato, o autor considera que dos dois modos sob os quais, para o filósofo grego, se articula cada potência, seria decisiva, para Agamben, a que o primeiro denomina "potência de não ser". Ora, toda potência é, - explica o autor -, ao mesmo tempo, "potência de ser" e "potência de não ser". Quando "potência de ser", a potência se realiza num determinado ato, pois, neste caso, "ser-em-ato" não significa outra coisa senão passar a esse ato determinado, o que Schelling considera uma potência "cega", uma vez que não pode não passar ao ato. Porém, quando "potência de não ser", a potência não se reduz jamais a um simples trânsito de potentia ad actum, razão pela qual, consoante Agamben, o que se tem aqui é uma potentia potentiae, uma potência cujo objeto é a própria potência.

O "caráter potencial" - de que fala o autor - do ser qualquer, consiste, sendo assim, justamente em ser essa potência do não, potência que tem por objeto a própria potência, portanto uma potência suprema, já que tanto pode a potência como a própria impotência. $\mathrm{O}$ ser que pode não ser encontra sua expressão radical, na literatura, na figura de Bartleby, famoso personagem de Herman Melville, escrivão que a todas as ordens e pedidos que lhe são dirigidos responde simplesmente não, que "preferiria não", não escrevendo outra coisa, desse modo, que a sua potência de não escrever. Bartleby é, nesse sentido, o rasum tabulae de que fala Aristóteles em De anima, a tábua de escrever na qual nada está escrito e que representa, pois, a pura potência do pensamento, que não é apenas a "potência de pensar este ou aquele inteligível", desaparecendo, assim, desde logo no ato, mas que é "também potência de não pensar".

É graças a essa potência de não pensar que o pensamento pode voltar-se para si mesmo (para a sua pura potência) e ser, no seu extremo apogeu, pensamento do pensamento. Isso que aqui ele pensa não é, porém, um objeto, um ser-em-ato, mas aquela camada de cera, aquele rasum tabulae, que não é outra coisa senão a própria passividade, a própria pura potência (de não pensar): na potência que pensa a si mesma, ação e paixão se identificam e a tabuleta para escrever se escreve por si ou, antes, escreve a sua própria passividade (idem, p. 41).

BRANDÃO, Alessandra Soares; LUZ, Júlio César Alves da. A comunidade das singularidades quaisquer: a comunidade que vem de Giorgio Agamben. Crítica Cultural - Critic, Palhoça, SC, v. 9, n. 2, p. 339-343, jul./dez. 2014. 
O ser passivo, aqui em questão, não se confunde, porém, com o ser alienado e conformado. Bartleby não é, nesse sentido, simplesmente passivo, ele "escreve a sua própria passividade", é sujeito em sua potência do não, potência que se volta para si, que pensa a si mesma. Desse modo, Bartleby representa a política da passividade que constitui o viés sob o qual Agamben considera o horizonte político da singularidade qualquer. De acordo com Antelo, a figura de Bartleby é o emblema da comunidade que vem:

Bartleby é a fórmula da potência passiva porque ele permite o direito de não resposta, em que Agamben reconhece a soberania extrema. [...] para Giorgio Agamben, o ato perfeito de escritura não deriva da potência de escrever, mas de uma impotência voltada para si própria. A política que vem é em suma a de uma potência sem qualquer relação com o ato, uma pura força-de-lei, aquilo que Derrida, Deleuze e o mesmo Agamben identificam com a posição Bartleby (2007, p. 43).

A figura de Bartleby coloca em questão, pois, e nos leva a pensar numa diferente forma de sociabilidade. Ora, se a comunidade que vem, como a concebe Agamben, deva se encontrar privada de qualquer reivindicação identitária e não possa ser mediada por nenhuma condição de pertença, senão a própria pertença, um novo horizonte político, então, descortina-se às singularidades quaisquer, isso num contexto em que os novos paradigmas políticos devem refutar, para o autor, propostas comunitárias que ignoram e/ou produzem violência sobre as singularidades.

Os acontecimentos de Maio em Pequim, para o filósofo, são significativos como expressão desse novo contexto político. Sob a atmosfera efervescente do convulso processo de colapso do bloco comunista, em maio de 1989 milhares de estudantes chineses ocuparam a praça da Paz Celestial, sede de alguns dos principais órgãos do poder estatal. Os manifestantes, em greve de fome, exigiam reformas democráticas; porém, tomando vulto, o movimento reuniu, no dia 20 , cerca de um milhão de pessoas em apoio aos protestos, e o governo chinês, de forma totalitária e truculenta, reagiu violentamente, avançando com veículos de guerra e abrindo fogo contra a multidão. A imprevista inexplicável violência da reação estatal aos manifestantes chineses - por sua vez sob a aparente inexplicável ausência de conteúdos em suas reivindicações exprimiria, segundo Agamben, as novas condições em que se instauram, então, os conflitos entre o Estado e o não-Estado. "Pois", como explica o autor, "o fato novo da política que vem é que ela não será mais a luta pela conquista ou pelo controle do Estado, mas a luta entre o Estado e o não-Estado (a humanidade), disjunção irremediável entre as singularidades quaisquer e a organização estatal" (2013, p. 78, grifos do autor).

O Estado, ressalta o filósofo, pode reconhecer, em última instância, qualquer reivindicação identitária; o que não pode admitir, pelo contrário, é justamente que as singularidades formem comunidade sem a fundamentarem numa identidade representável, sem reivindicarem condição alguma de pertença. "Por isso, relevante não é jamais a singularidade como tal, mas somente a sua inclusão em uma identidade qualquer (mas que o próprio qualquer seja retomado sem uma identidade - essa é uma 
ameaça com a qual o Estado não está disposto a compactuar)" (idem, p. 79). Ora, se as singularidades quaisquer não podem constituir uma sociedade já que estão privadas de qualquer identidade que possam reconhecer; se essas singularidades refutam toda condição de pertença e querem, na verdade, apropriar-se da própria pertença enquanto tal - elas representam, portanto, o principal inimigo do Estado.

Assim se configuram, pois, para Agamben, as novas condições políticas e, também, as novas possibilidades de luta num contexto em que não corresponderiam mais, como no passado, àquelas que se caracterizavam pelo embate dialético das lutas de classes. Ainda que pareça uma desproporção esmagadora, esta cisão que põe em conflito - nas palavras do autor - o Estado e o não-Estado, as singularidades, embora pareçam tão mínima força, constituem, pelo contrário, no comum do corpo biopolítico que - segundo Antonio Negri e Michael Hardt - as somam em Multidão, biopotência coletiva, a soma de todas as potências singulares que, na ordem global contemporânea, ameaçam o biopoder estatal. Dadas as novas configurações políticas, circunscritos os desejos e necessidades que cada luta, em sua especificidade, expressa, as novas formas de luta realizam, agora, um movimento diferente: "impedidas de viajar horizontalmente na forma de ciclo", como outrora, hoje "elas se vêem forçadas a uma expansão vertical e a tocar imediatamente no nível global" (NEGRI; HARDT, 2010, p. 74). "Lutas serpentinas", como as denominam os autores, formas de resistência que, então, porque prescindem da formação de uma corrente, atacam diretamente o centro do poder que procura controlar a vida; o perigo maior que pode colocar em cheque, de acordo com Agamben, o poder do Estado, essa potencialidade despertada em cada vida singular, como naquele jovem chinês diante de uma coluna de tanques nos eventos de maio em Pequim.

\section{REFERÊNCIAS}

AGAMBEN, Giorgio. A Comunidade que vem. Trad. de Cláudio Oliveira. Belo Horizonte: Autêntica Editora, 2013.

Homo sacer: o poder soberano e a vida nua I. 2. ed. Belo Horizonte: UFMG, 2010.

ANTELO, Raul. La comunità che viene: ontologia da potência. In: SEDLMAYER, Sabrina; GUIMARÃES, César; OTTE, Georg (org.). O Comum e a experiência da linguagem. Belo Horizonte: Editora UFMG, 2007.

DIDI-HUBERMAN, Georges. Sobrevivência dos vaga-lumes. Belo Horizonte: UFMG, 2011.

HARDT, Michael; NEGRI, Antonio. Império. 9. ed. Rio de Janeiro: Record, 2010.

Recebido em 25/10/2014. Aprovado em 10/11/2014.

BRANDÃO, Alessandra Soares; LUZ, Júlio César Alves da. A comunidade das singularidades quaisquer: a comunidade que vem de Giorgio Agamben. Crítica Cultural - Critic, Palhoça, SC, v. 9, n. 2, p. 339-343, jul./dez. 2014. 